\title{
RAINBOW CONNECTION PADA GRAF DENGAN KONEKTIFITAS 1
}

\author{
VOENID DASTI \\ Program Studi Matematika, \\ Fakultas Matematika dan Ilmu Pengetahuan Alam, Universitas Andalas, \\ Kampus UNAND Limau Manis Padang, Indonesia, \\ infrenchasfasthetwinklingofaneye@yahoo.com
}

\begin{abstract}
Abstrak. Misal terdapat graf terhubung sederhana $G$. Jika diberikan pewarnaan terhadap sisi-sisi $G$ sehingga sebarang dua titik di $G$ dihubungkan oleh suatu lintasan dengan semua sisi berwarna berbeda, maka $G$ dikatakan rainbow connected. Rainbow connection number dari graf $G$, dinotasikan dengan $r c(G)$, adalah minimum dari banyaknya warna yang dibutuhkan untuk mewarnai $G$ sehingga $G$ bersifat rainbow connected. Dalam skripsi ini akan dibahas kembali dugaan Caro dkk [3] bahwa $r c(G)<\frac{3 n}{4}$ untuk suatu graf terhubung tak trivial $G$ dengan banyak titik $n$, derajat minimum $\delta(G) \geq 3$, dan konektifitas $\kappa(G)=1$.
\end{abstract}

Kata Kunci: Konektifitas, Rainbow coloring, Rainbow connection number

\section{Pendahuluan}

Misalkan $G=(V(G), E(G))$ adalah suatu graf terhubung tak-trivial. Suatu pewarnaan terhadap sisi-sisi di $G$ didefinisikan sebagai $c: E(G) \rightarrow\{1,2, \cdots, k\}, k \in \mathbb{N}$, dimana dua sisi yang bertetangga boleh berwarna sama. Suatu lintasan $u-v P$ di $G$ dinamakan rainbow path jika tidak terdapat dua sisi di $P$ yang berwarna sama. Graf $G$ disebut rainbow connected dengan pewarnaan $c$ jika $G$ memuat suatu rainbow $u$-v path untuk setiap dua titik $u, v \in G$. Dalam hal ini, pewarnaan $c$ dikatakan rainbow coloring di $G$. Jika terdapat $k$ warna di $G$ maka $c$ dikatakan rainbow $k$ coloring. Minimum $k$ sehingga terdapat rainbow $k$-coloring di $G$ disebut rainbow connection number, ditulis $r c(G)$. Suatu rainbow coloring yang menggunakan $r c(G)$ warna dikatakan minimum rainbow coloring di $G$ [2].

Misalkan $c$ suatu rainbow coloring pada suatu graf terhubung $G$. Untuk sebarang dua titik $u$ dan $v$ di $G$, rainbow $u$-v geodesic di $G$ adalah suatu rainbow path dengan panjang $d(u, v)$, di mana $d(u, v)$ adalah jarak antara $u$ dan $v$. Graf $G$ dikatakan strongly rainbow connected jika $G$ memuat satu rainbow u-v geodesic untuk setiap dua titik $u$ dan $v$ pada $G$. Dalam kasus ini, pewarnaan $c$ disebut pewarnaan strong rainbow coloring pada $G$. Minimum $k$ sehingga terdapat pewarnaan yang menyebabkan $G$ bersifat strongly rainbow connected disebut strong rainbow connection number graf $G$, dinotasikan dengan $\operatorname{src}(G)$. Dari definisi, jelas bahwa $r c(G) \leq \operatorname{src}(G)$ untuk setiap graf terhubung $G$.

Hubungan $\operatorname{diam}(G), \operatorname{rc}(G), \operatorname{src}(G)$ dan banyak sisi $m$ pada suatu graf terhubung 
$G$ ditunjukkan oleh pertidaksamaan berikut [2]:

$$
\operatorname{diam}(G) \leq r c(G) \leq \operatorname{src}(G) \leq m .
$$

Konsep rainbow connection dapat digunakan untuk pengamanan pengiriman informasi rahasia antar lembaga. Selain itu, rainbow connection dimotivasi oleh interpretasi menarik di bidang jaringan. Misalkan $G$ diinterpretasikan sebagai suatu jaringan (misalnya, jaringan selular). Akan disampaikan rute pesan antara dua titik penerima, acceptor, dengan syarat bahwa rute antara kedua titik (atau dapat dilihat sebagai sisi pada path), diberikan suatu saluran yang berbeda (misalnya, frekuensi yang berbeda). Jelas bahwa yang ingin diminimalkan adalah banyaknya saluran berbeda yang digunakan dalam jaringan. Bilangan ini adalah rainbow connection number $\operatorname{rc}(G)$ [3]. Dalam tulisan ini dikaji kembali tentang rainbow connection pada graf dengan konektivitas 1.

\section{Rainbow Connection pada Graf dengan Konektivitas 1}

Pada suatu graf $G$ dengan konektivitas $\kappa(G)=1$, yaitu graf yang memiliki cut vertex, konsep rainbow connection diperluas dengan menambahkan syarat, yaitu untuk sebarang dua sisi di $G$, sisi-sisi tersebut memiliki warna berbeda bilamana berada pada blok yang berbeda di G. Rainbow connection number yang bersesuaian dengan penambahan syarat ini dinotasikan dengan $r c^{*}(G)$. Dari definisi, jelas bahwa $r c(G) \leq r c^{*}(G)$ untuk setiap graf $G$ dan $r c(G)=r c^{*}(G)$ untuk setiap graf 2-connected $G$. Untuk graf dengan $\kappa(G)=1$, akan dibuktikan kembali teorema berikut.

Teorema 2.1. [5] Jika $G$ suatu graf terhubung dengan $n$ titik, $\kappa(G)=1$, dan $\delta(G) \geq 3$, maka rc $c^{*}(G) \leq \frac{3 n-10}{4}$.

Batas $\frac{3 n-10}{4}$ tidak dapat dikurangkan karena terdapat graf terhubung 3-regular dengan $r c(G)=r c^{*}(G)=\operatorname{diam}(G)=\frac{3 n-10}{4}$. Graf terhubung $3-$ regular tersebut dapat dikonstruksi dengan langkah-langkah berikut. Misal terdapat dua kopi graf $K_{5}-\left(P_{3} \cup P_{2}\right)$. Berikan label pada dua titik berderajat 2 di graf tersebut dengan $w_{1}$ dan $w_{2 k+2}$, di mana $k$ adalah bilangan bulat positif. Hubungkan $w_{1}$ dan $w_{2 k+2}$ melalui suatu lintasan dengan panjang $2 k+1$ dan beri label titik-titik pada lintasan tersebut dengan $w_{1}, w_{2}, \cdots,, w_{2 k+2}$. Untuk $1 \leq i \leq k$, setiap sisi $w_{2 i} w_{2 i+1}$ diganti dengan suatu graf $K_{4}-e$ dan labeli dua titik yang berderajat 2 di $K_{4}-e$ dengan $w_{2 i}$ dan $w_{2 i+1}$. Graf yang diperoleh dari proses di atas adalah graf $G_{4 k+10}$ yang merupakan graf terhubung $3-$ regular dengan $n=4 k+10$ dan

$$
r c^{*}\left(G_{4 k+10}\right)=r c\left(G_{4 k+10}\right)=\operatorname{diam}\left(G_{4 k+10}\right)=3 k+5=\frac{3 n-10}{4} .
$$

Sebelum membuktikan Teorema 2.1 diatas, terlebih dulu dibuktikan Proposisi 2.2 dan Akibat 2.3 berikut.

Proposisi 2.2. [5] Misalkan $G$ suatu graf 2-connected dengan banyak titik $n$ dan barisan derajatnya $2 \leq d_{1} \leq d_{2} \leq \cdots \leq d_{n}$. Jika $d_{3} \geq 3$ maka $r c(G) \leq \frac{2 n-2}{3}$ untuk $4 \leq n \leq 7$ dan $r c(G) \leq \frac{2 n-1}{3}$ untuk $n \geq 8$. 
Bukti. Misalkan $H$ suatu subgraf terhubung maksimal dari $G$ dan $r c(H) \leq \frac{2 h}{3}-1$ dengan $h$ adalah banyak titik di $H$. Klaim $H$ tersebut ada. Karena $G$ suatu graf 2-connected dan $d_{3} \geq 3$, maka $n \geq 4$. Berdasarkan teorema Dirac [4], circumference $c(G)$ pada $G$ memenuhi $c(G) \geq \min \{n, 2 \delta(G)\} \geq 4$. Selanjutnya, pandang beberapa kasus berikut.

(Kasus 1.) Jika $n=4$, maka $r c(G) \leq 2 \leq \frac{2.4-2}{3}$.

(Kasus 2.) Jika $n=5=c(G)$ maka $G$ memuat $C_{5}+e$ sebagai subgraf sehingga $r c(G) \leq$ $2 \leq \frac{2.5-2}{3}$.

(Kasus 3.) Untuk $n>5$, perhatikan beberapa sub-kasus berikut.

(SubKasus 1) Jika $c(G)=5$, maka dengan menjadikan $H$ sebagai $C_{5}$ dengan suatu sisi yang ditambahkan, diperoleh $r c(H)=3=\frac{2.6}{3}-1$.

(SubKasus 2) Jika $c(G) \in\{6,8\}$ maka jadikan subgraf $H$ sebagai $C_{k}$, diperoleh $r c\left(C_{k}\right)=\frac{k}{2} \leq \frac{2 k}{3}-1$ untuk $k=6,8$.

(SubKasus 3) Jika $c(G)=7=n$ maka jadikan $C_{7}$ sebagai $H$. Diperoleh $r c\left(C_{7}\right)=$ $4=\frac{2.7-2}{3}$.

(SubKasus 4) Jika $c(G)=7<n$ maka dengan menjadikan $H$ sebagai suatu graf $C_{7}$ dengan suatu sisi yang ditambahkan, didapat $r c(H)=4<\frac{2.8}{3}-1$.

(SubKasus 5) Jika $c(G)=k \geq 9$ maka jadikan $C_{k}$ sebagai $H$, diperoleh $r c\left(C_{k}\right)=$ $\left\lceil\frac{k}{2}\right\rceil \leq \frac{k+1}{2} \leq \frac{2 k}{3}-1$.

Klaim bahwa $h \geq n-2$. Andaikan $h<n-2$. Berarti terdapat tiga titik berbeda yang terletak di luar $H$, katakanlah titik-titik $w_{1}, w_{2}, w_{3}$ yang masing-masing memiliki dua tetangga yang berada di dalam $H$ (tetangga-tetangga dari titik $w_{i}$ tidak perlu berbeda dengan tetangga-tetangga dari titik $w_{j}$ ). Titik-titik $w_{1}, w_{2}, w_{3}$ dapat ditambahkan ke graf $H$ sehingga terbentuk suatu subgraf yang lebih besar, dinotasikan dengan $H^{\prime}$, yang memiliki $h+3$ titik. Misalkan $e_{i}, f_{i}$ adalah dua sisi yang menghubungkan $w_{i}$ dengan $H$. Dua warna dapat digunakan untuk mewarnai keenam sisi, yaitu $e_{1}, e_{2}, e_{3}$ diwarnai dengan warna yang sama dan $f_{1}, f_{2}, f_{3}$ memiliki warna lain yang sama pula. Diperoleh

$$
r c\left(H^{\prime}\right) \leq r c(H)+2 \leq \frac{2 h}{3}-1+2=\frac{2(h+3)}{3}-1,
$$

yang merupakan kontradiksi dengan pernyataan bahwa $H$ merupakan subgraf maksimal. Ini berarti bahwa jika terdapat tiga titik diluar $H$ maka sekurang-kurangnya salah satu dari titik-titik tersebut, katakanlah $w$, memiliki sifat bahwa untuk suatu lintasan terpendek dari $H$ ke $H$ yang melewati $w$, panjangnya tidak kurang dari 3 (perhatikan bahwa pasti terdapat lintasan karena $G$ adalah graf 2-connected).

Misalkan $u w_{1} w_{2} \cdots w_{t} v$ suatu lintasan dengan $u, v \in V(H), w_{1}, \cdots, w_{t} \notin V(H)$ dan $t \geq 2$. Titik-titik $w_{1}, \cdots, w_{t}$ ditambahkan ke $H$ sehingga membentuk suatu subgraf $H^{\prime}$ yang lebih besar dengan $h+t$ titik.

Jika $t$ ganjil maka $t+1$ sisi pada lintasan diberi warna menggunakan $\frac{t+1}{2}$ warnawarna baru. Pada setengah panjang lintasan, beri warna berbeda pada sisi-sisi nya, dan urutan warna yang sama diwarnakan pada setengah panjang lintasan sisanya. Hal ini menunjukkan bahwa $H^{\prime}$ bersifat rainbow connected. 
Jika $t$ genap maka $t+1$ sisi pada lintasan diberi warna menggunakan $\frac{t}{2}$ warna dengan aturan sebagai berikut : sisi $w_{t / 2} w_{t / 2+1}$ yang berada di tengah lintasan diberi warna menggunakan sebarang warna yang sudah muncul di $H$. Sebanyak $\frac{t}{2}$ sisi-sisi pertama pada lintasan diberi warna menggunakan warna baru yang berbeda dan pada $\frac{t}{2}$ sisi-sisi terakhir, warna-warna tersebut diulang dengan urutan yang sama. Proses ini menunjukkan bahwa $H^{\prime}$ bersifat rainbow connected dan diperoleh:

$$
r c\left(H^{\prime}\right) \leq r c(H)+\left\lceil\frac{t}{2}\right\rceil \leq \frac{2 h}{3}-1+\left\lceil\frac{t}{2}\right\rceil \leq \frac{2(h+t)}{3}-1,
$$

yang merupakan kontradiksi dengan pernyataan bahwa $H$ subgraf maksimal. Jadi, haruslah $h \geq n-2$.

Untuk $h \geq n-2$ diperoleh

- jika $h=n-2$, maka $r c(G) \leq r c(H)+2 \leq \frac{2(n-2)}{3}-1+2=\frac{2 n-1}{3}$,

- jika $h=n-1$, maka $r c(G) \leq r c(H)+1 \leq \frac{2(n-1)}{3}-1+1=\frac{2 n-2}{3}$,

- jika $h=n$, maka $r c(G) \leq r c(H)=\frac{2 n}{3}-1<\frac{2 n-1}{3}$.

Jadi, diperoleh bahwa $r c(G) \leq \frac{2 n-2}{3}$ untuk $4 \leq n \leq 7$ dan $r c(G) \leq \frac{2 n-1}{3}$ untuk $n \geq 8$.

Dari Proposisi 2.2 diperoleh Akibat 2.3 berikut.

Akibat 2.3. [5] Misalkan $G$ suatu graf 2-connected dengan banyak titik $n$ dan barisan derajat $2 \leq d_{1} \leq d_{2} \leq \cdots \leq d_{n}$. Jika $d_{3} \geq 3$, maka $r c(G) \leq \frac{3 n-4}{4}$.

Berikut akan ditentukan struktur dari endblocks. Endblock adalah blok yang mempunyai tepat satu titik potong. Blok yang bukan endblock disebut inner block Notasikan

$$
\mathfrak{B}=\left\{K_{4}, K_{5}, K_{5}-e, K_{5}-P_{3}, K_{5}-2 P_{2}, K_{5}-\left(P_{3} \cup P_{2}\right)\right\} .
$$

Karena $K_{4}, K_{5}$ merupakan graf lengkap, maka $r c\left(K_{4}\right)=r c\left(K_{5}\right)=1$. Kemudian, $r c\left(K_{5}-e\right)=r c\left(K_{5}-P_{3}\right)=r c\left(K_{5}-2 P_{2}\right)=r c\left(K_{5}-\left(P_{2} \cup P_{3}\right)\right)=2$.

Untuk $B \in \mathfrak{B}$, misalkan $B \cup K_{2}$ suatu endblock dengan penambahan $K_{2}$. Jika $B \in\left\{K_{4}, K_{5}, K_{5}-e, K_{5}-2 P_{2}\right\}$ maka $K_{2}$ dapat ditambahkan ke sebarang titik di B. Jika $B \in\left\{K_{5}-P_{3}, K_{5}-\left(P_{3} \cup P_{2}\right)\right\}$ maka $K_{2}$ dapat ditambahkan pada titik berderajat 2 dalam $K_{5}-P_{3}$ atau $K_{5}-\left(P_{3} \cup P_{2}\right)$. Sekarang, klaim berikut dapat dibuktikan.

Klaim 2.4. Misalkan $G$ suatu graf terhubung dengan $\delta(G) \geq 3$. Jika $G=G_{1} \cup G_{2}$ dengan $V\left(G_{1}\right) \cap V\left(G_{2}\right)=w$ untuk $w$ suatu cut vertex dan $\left|V\left(G_{1}\right)\right| \leq 6$, maka $G_{1} \cong B$ atau $G_{1} \cong B \cup K_{2}$ untuk beberapa $B \in \mathfrak{B}$.

Klaim 2.5. Jika $B \in \mathfrak{B}$ suatu endblock maka $\operatorname{rc}(B) \leq \frac{3 n-7}{4}$ dan $\operatorname{rc}\left(B \cup K_{2}\right) \leq$ $\frac{3 n-6}{4}$.

Sekarang akan dibuktikan Teorema 2.1.

Bukti. Perhatikan klaim di bawah. Pada subgraf $F \subset G, n(F)$ adalah notasi untuk banyaknya titik di $F$. 
Klaim 2.6. Misalkan $G$ suatu graf terhubung dengan suatu titik potong $w$. Jika $G=G_{1} \cup G_{2}$ dan $V\left(G_{1} \cup G_{2}\right)=w, d_{G_{1}}(w) \geq 2, d_{G_{2}}(w) \geq 1, V\left|\left(G_{1}\right)\right| \geq 6$ dan $V\left|\left(G_{2}\right)\right| \geq 7$, maka diperoleh $r c^{*}(G) \leq \frac{3 n-10}{4}$.

Bukti. (Klaim 2.6) Konstruksi dua graf, yaitu $H_{1}$ dan $H_{2}$ dengan langkah berikut. Misalkan $H_{1} \cong\left(K_{5}-P_{3}\right) \cup G_{2}$. Identifikasi titik berderajat 2 dalam $K_{5}-P_{3}$ dengan $w$ dari $G_{2}$. Selanjutnya, misal $H_{2} \cong G_{1} \cup K_{2} \cup\left(K_{5}-P_{3}\right)$. Identifikasi suatu titik di $K_{2}$ dengan $w$ di $G_{1}$ dan identifikasi titik lain dari $K_{2}$ dengan titik berderajat dua dalam $K_{5}-P_{3}$. Diperoleh

$$
\begin{aligned}
& \left|V\left(H_{1}\right)\right|=\left|V\left(K_{5}-P_{3}\right)\right|+\left|V\left(G_{2}\right)\right|-1<\left|V\left(G_{1}\right)\right|+\left|V\left(G_{2}\right)\right|-1=|V(G)| \text { dan } \\
& \left|V\left(H_{2}\right)\right|=\left|V\left(\left(K_{5}-P_{3}\right) \cup K_{2}\right)\right|+\left|V\left(G_{1}\right)\right|-1<\left|V\left(G_{2}\right)\right|+\left|V\left(G_{1}\right)\right|-1=|V(G)| .
\end{aligned}
$$

Selanjutnya, dengan induksi didapat

$$
r c^{*}\left(H_{1}\right) \leq \frac{3 n\left(H_{1}\right)-10}{4}, \operatorname{dan} r c^{*}\left(H_{2}\right) \leq \frac{3 n\left(H_{2}\right)-10}{4},
$$

yang mengakibatkan

$$
\begin{aligned}
& r c^{*}\left(G_{2}\right) \leq \frac{3\left(n\left(G_{2}\right)+4\right)-10}{4}-2=\frac{3 n\left(G_{2}\right)-6}{4}, \text { dan } \\
& r c^{*}\left(G_{1}\right) \leq \frac{3\left(n\left(G_{1}\right)+5\right)-10}{4}-3=\frac{3 n\left(G_{1}\right)-7}{4} .
\end{aligned}
$$

Hasil ini memberikan:

$$
\begin{aligned}
r c^{*}(G)=r c^{*}\left(G_{1}\right)+r c^{*}\left(G_{2}\right) & \leq \frac{3 n\left(G_{1}\right)-7}{4}+\frac{3 n\left(G_{2}\right)-6}{4} \\
& =\frac{3\left(n\left(G_{1}\right)+n\left(G_{2}\right)-1\right)-10}{4}=\frac{3 n-10}{4} .
\end{aligned}
$$

Berikut ini ditelaah graf pohon blok $T$ dari $G$.

Misalkan $V(T)=\left\{w_{1}, w_{2}, \cdots, b_{1}, b_{2}, \cdots\right\}$, di mana $w_{i}$ adalah suatu titik potong pada $G$ dan $b_{i}$ merupakan blok $B_{i}$ dari $G$. Ini berarti $w_{i} b_{j} \in E(T)$ jika dan hanya jika $w_{i}$ terkait dengan $B_{j}$ di dalam $G$. Perhatikan beberapa observasi berikut.

Observasi 2.7. Jika $B_{i}$ suatu endblock dari $G\left(b_{i}\right.$ merupakan daun dari $\left.(T)\right)$ maka $\mid V\left(B_{i} \mid \geq 4\right.$, karena $\delta \geq 3$.

Observasi 2.8. Jika $d_{T}(w) \geq 4$ untuk suatu titik potong $w$ dari $G$, maka $G=$ $G_{1} \cup G_{2}$ dengan $G_{1} \cap G_{2}=w$ serta kedua graf $G_{1}$ dan $G_{2}$ memuat paling sedikit dua blok tak trivial. Kemudian $\left|V\left(G_{i}\right)\right| \geq 2.4-1=7$ untuk $i=1,2$. Jadi, dapat diasumsikan bahwa $2 \leq d_{T}(w) \leq 3$ untuk setiap titik potong $w$.

Observasi 2.9. Jika titik potong $w$ berderajat 3, maka $G=G_{1} \cup G_{2} \cup G_{3}$. Dari argumen pada Observasi 2.8 di atas, masing-masing $G_{i}$ memuat tepat satu blok tak-trivial yang merupakan endblock. Jadi $\left|V\left(G_{i}\right)\right| \leq 6$ untuk $1 \leq i \leq 3$. Dari $|V(G)|=\left|V\left(G_{1}\right)\right|+\left|V\left(G_{2}\right)\right|+\left|V\left(G_{3}\right)\right|-2$ didapatkan

$$
r c^{*}(G) \leq \frac{3 n\left(G_{1}\right)-6}{4}+\frac{3 n\left(G_{2}\right)-6}{4}+\frac{3 n\left(G_{3}\right)-6}{4}=\frac{3 n-12}{4}<\frac{3 n-10}{4} .
$$


Observasi 2.10. Jika suatu titik b (yang berkaitan dengan suatu blok B) berderajat $p \geq 3$ maka $B$ terkait dengan $p$ titik potong $w_{1}, w_{2}, \cdots, w_{p}$, sehingga $G=B \cup G_{1} \cup$ $G_{2} \cup \cdots \cup G_{p}$. Oleh karena itu diperoleh

$$
r c^{*}(G) \leq \frac{2 n(B)}{3}+\Sigma^{p}{ }_{i=1} \frac{3 n\left(G_{i}\right)-6}{4} \leq \frac{3 n(B)-1}{4}+\frac{3(n+p-n(B))-6 p}{4}=\frac{3 n-1-3 p}{4} \leq \frac{3 n-10}{4} .
$$

Jadi, dapat diasumsikan bahwa $\Delta(T)=2$ dan dengan demikian $T$ adalah suatu lintasan. $G$ memuat paling banyak satu inner block tak-trivial $B$. Jadi untuk lintasan $T$, struktur-struktur blok berikut dapat terbentuk.

(1) Jika struktur blok berbentuk $B_{1}, B_{2}$, maka

$$
r c^{*}(G) \leq \frac{3 n\left(B_{1}\right)-7}{4}+\frac{3 n\left(B_{2}-7\right)}{4}=\frac{3 n-11}{4}<\frac{3 n-10}{4} .
$$

(2) Jika struktur blok pada $T$ berbentuk $B_{1}, K_{2}, B_{2}$, maka

$$
r c^{*}(G) \leq \frac{3 n\left(B_{1} \cup K_{2}\right)-6}{4}+\frac{3 n\left(B_{2}\right)-7}{4}=\frac{3 n-10}{4} .
$$

(3) Jika struktur blok pada $T$ berbentuk $B_{1}, B, B_{2}$, maka

$$
r c^{*}(G) \leq \frac{3 n\left(B_{1}\right)-7}{4}+\frac{3 n(B)-4}{4}+\frac{3 n\left(B_{2}\right)-7}{4}=\frac{3 n-12}{4}<\frac{3 n-10}{4} .
$$

(4) Jika struktur blok pada $T$ berbentuk $B_{1}, K_{2}, B, B_{2}$, maka

$$
r c^{*}(G) \leq \frac{3 n\left(B_{1} \cup K_{2}\right)-4}{4}+\frac{3 n(B)-6}{4}+\frac{3 n\left(B_{2}\right)-7}{4}=\frac{3 n-11}{4}<\frac{3 n-10}{4} .
$$

(5) Jika struktur blok pada $T$ berbentuk $B_{1}, K_{2}, B, K_{2}, B_{2}$, maka

$$
r c^{*}(G) \leq \frac{3 n\left(B_{1} \cup K_{2}\right)-6}{4}+\frac{3 n(B)-4}{4}+\frac{3 n\left(B_{2} \cup K_{2}\right)-6}{4}=\frac{3 n-10}{4} .
$$

\section{Kesimpulan}

Pada makalah ini telah dikaji kembali dugaan Caro dkk. [3] bahwa untuk suatu graf terhubung tak-trivial $G$ dengan banyak titik $n$, konektivitas $\kappa(G)=1$, serta derajat minimum $\delta(G) \geq 3$, berlaku bahwa $r c^{*}(G) \leq \frac{3 n}{4}$, di mana $r c^{*}(G)$ adalah rainbow connection number, yaitu minimum dari banyaknya warna yang diperlukan agar $G$ bersifat rainbow connected, dengan syarat setiap blok pada $G$ menerima warna yang berbeda.

\section{Ucapan Terima Kasih}

Penulis mengucapkan terima kasih kepada Ibu Lyra Yulianti, Bapak Zulakmal, Bapak Admi Nazra, Bapak Syafrizal Sy dan Bapak Mahdhivan Syafwan yang telah memberikan masukan dan saran sehingga paper ini dapat diselesaikan dengan baik. 
98 Voenid Dasti

\section{Daftar Pustaka}

[1] Bondy, J.A., U.S.R. Murty. 1976. Graph Theory with Applications. Elsevier Science Publishing, New York

[2] Chartrand, G., Kalamazoo, G.L. Johns, S Valley, K.A. McKeon. 2006. Rainbow Connection in Graphs. Mathematica Bohemica, New London. 15 : 85 - 89

[3] Caro, Y., A. Lev, Y. Roditty, Z Tuza, R. Yuster. 2008. On Rainbow Connection. The Electronic Journal of Combinatorics $57: 1-13$

[4] Schiermeyer, I. 2008. Rainbow Connection in Graph with Minimum Degree Three. Lecture Notes On Computer Sciences. Springer-Verlag Berlin. 5874: 432 - 437 